\title{
Family history and risk of bladder cancer: an analysis accounting for first- and second- degree relatives
}

\author{
Authors \\ Evan Yi-Wen Yu ${ }^{1,2,3 \dagger}$, Mariana C. Stern ${ }^{4}$, Xuejuan Jiang ${ }^{5,6}$, Li Tang ${ }^{7}$, Piet A. van den Brandt ${ }^{8,9}$, Chih- \\ Ming Lu ${ }^{10}$, Margaret R. Karagas ${ }^{11}$, Carlo La Vecchia ${ }^{12}$, Cristina Bosetti ${ }^{13}$, Jerry Polesel ${ }^{14}$, Klaus Golka \\ ${ }^{15}$, Zuo-Feng Zhang ${ }^{16}$, Paul Villeneuve ${ }^{17}$, Maurice P. Zeegers ${ }^{2,3,18}$, Anke Wesselius ${ }^{2}$
}

\section{Affiliations of all authors}

1 Key Laboratory of Environmental Medicine and Engineering of Ministry of Education, Department of Epidemiology \& Biostatistics, School of Public Health, Southeast University, Nanjing, China.

2 School of Nutrition and Translational Research in Metabolism, Maastricht University, Maastricht, the Netherlands.

3 CAPHRI Care and Public Health Research Institute, Maastricht University, Maastricht, the Netherlands.

4 Department of Preventive Medicine, Norris Comprehensive Cancer Center, Keck School of Medicine of USC, University of Southern California, Los Angeles, CA, USA.

5 USC Roski Eye Institute, Department of Ophthalmology, University of Southern California, Los Angeles, CA, USA.

6 Department of Preventive Medicine, University of Southern California, Los Angeles, CA, USA.

7 Department of Cancer Prevention and Control, Roswell Park Comprehensive Cancer Center, Buffalo, NY, USA.

8 Department of Epidemiology, Maastricht University Medical Centre, GROW- School for Oncology and Developmental Biology, Maastricht, The Netherlands.

9 Department of Epidemiology, Maastricht University Medical Centre, Care and Public Health Research Institute (CAPHRI), Maastricht, the Netherlands.

10 Department of Urology, Buddhist Dalin Tzu Chi General Hospital, Chiayi County, Taiwan, China. 11 Department of Epidemiology, Geisel School of Medicine at Dartmouth, Hanover, NH, USA. 12 Department of Clinical Medicine and Community Health, University of Milan, Milan, Italy. 
13 Department of Oncology, Istituto di Ricerche Farmacologiche Mario Negri IRCCS, Milan, Italy.

14 Unit of Cancer Epidemiology, Centro di Riferimento Oncologico di Aviano (CRO) IRCCS, Italy.

15 Leibniz Research Centre for Working Environment and Human Factors at TU Dortmund, Dortmund, Germany.

16 Departments of Epidemiology, UCLA Center for Environmental Genomics, Fielding School of Public Health, University of California, Los Angeles (UCLA), Los Angeles, CA, USA.

17 School of Mathematical \& Statistics, Carleton University, Ottawa, Canada.

18 School of Cancer Sciences, University of Birmingham, Birmingham, UK.

Running Title: Family history and bladder cancer

†Corresponding author: Evan Yi-Wen Yu

Mailing Address: Universiteitssingel 40, 6229 ER, Maastricht, the Netherlands.

Phone Number: +310613155188

E-mail address: Evan.Y.W.Yu@gmail.com

ORCID: https://orcid.org/0000-0001-7825-5087

\section{Conflict of interest}

All the authors declare that they have no conflicts of interest.

\section{Abbreviation}

OR: odds ratio; CI: confidence interval; BLEND: BLadder cancer Epidemiology and Nutritional Determinants; ICD: International Classification of Diseases; GWAS: genome-wide association study; SNP: single nucleotide polymorphisms; BMI: body mass index; SES: socioeconomic status. 


\begin{abstract}
Although evidence suggests that a positive family history of bladder cancer in first-degree relatives is an important risk factor for bladder cancer occurrence, results remain unclear. The influence of family history of non-bladder cancers and more distant relatives on bladder cancer risk is inconsistent. This research therefore, aims to increase the understanding of the association between family history and bladder cancer risk based on worldwide case-control studies. In total 4,327 cases and 8,948 non-cases were included. Pooled odds ratios (ORs), with corresponding 95\% confidence intervals (CIs), were obtained using multilevel logistic regression models, adjusted by age, sex, ethnicity, smoking status, and smoking packyears. The results show bladder cancer risk increased by having a first- or second-degree relative affected with bladder cancer (OR 2.72, 95\%CI 1.55-4.77 and OR 1.71, 95\%CI 1.22-2.40, respectively), and nonurologic cancers (OR 1.61, 95\%CI 1.19-2.18). Moreover, bladder cancer risk increased by number of cancers affected first-degree relatives (for 1 and >1 first-degree relatives: OR 1.42, 95\% CI 1.02-2.04; OR 2.67, 95\% CI 1.84-3.86, respectively). Our findings highlight an increased bladder cancer risk for a positive bladder cancer family history in first- and second-degree relatives, and indicate a possible greater effect for an increment of numbers of affected relatives.
\end{abstract}

Keywords: bladder cancer; family history; smoking; case-control study

\title{
Prevention Relevance
}

This study found a positive association between family history and bladder cancer in first- and seconddegree relatives, with an added effect attributed to smoking. Given the detriments of bladder cancer, at-risk individuals should receive family history screening and tobacco cessation and avoidance counseling. 


\section{Introduction}

Bladder cancer is the most common malignancy of the urinary tract and the seventh leading cause of death from cancer, with nearly 550,000 new diagnoses and 200,000 deaths per year worldwide $[1,2]$. Threequarters of all bladder cancer cases occur in men [3], and the incidence rate of bladder cancer is higher in the United States, Canada, and the European Union [4-7]. As with many solid tumours, bladder cancer incidence increases with age and it rarely occurs before the age of 40-50 years [8]. Given its high frequency of recurrence, bladder cancer is reported to be among the most expensive life-time treatment of all cancers which results in burden to the healthcare system [9].

Previous studies have revealed that genetic susceptibility might play an important role in the occurrence and development of bladder cancer [10]. However, studies assessing the influence of genetics on bladder cancer risk, using family history as a surrogate marker for genetic susceptibility, showed inconsistent results. Some epidemiological studies reported an increased bladder cancer risk for individuals with a positive family history of bladder and non-bladder cancer types [11-16], while an analysis within the Nordic Twin Study of Cancer-including 203,691 twins from nationwide registries in Denmark, Finland, Norway and Sweden-suggested that hereditability is weaker for bladder cancer (30\%) compared to other urologic cancer, such as renal cancer (38\%) and prostate cancer (57\%) [17]. Moreover, information on familial clustering of bladder cancer with other cancer types is still scanty. In addition, most of the studies only investigated the effect of first-degree relatives, thereby lacking evidence on the effects of more distant relatives on bladder cancer risk. Furthermore, the detailed information on smoking habits were not well considered when investigating the association of family history with bladder cancer risk in previous studies. The present study, therefore, aims to examine the association between history of bladder and other cancer types among first- and second-degree relatives and bladder cancer risk, using data from Bladder Cancer Epidemiology and Nutrition Determinants (BLEND) study.

\section{Material and methods}

\section{Study participants and data collection}

Data were derived from the BLEND, an international consortium that collected data on diet and bladder cancer, details of its methodology have been described elsewhere [18]. For the present study, 7 casecontrol and 1 case-cohort study (including 4,327 cases/8,948 non-cases) with information on family history 
of bladder cancer and non-bladder cancer in either first- or second-degree relatives were originated from 5 countries (i.e., USA[19-22], Italy [23, 24], Germany [25], the Netherlands [26], and China [27]) eligible for inclusion. Information on family history of bladder cancer and/or non-bladder cancer types (including urologic cancers: i.e. renal cancer and/or prostate cancer; non-urologic cancers: i.e. lip, oral cavity and pharynx cancer, oesophagus cancer, stomach cancer, intestinal cancer, colorectal cancer, liver cancer, gall bladder cancer, pancreas cancer, respiratory tract cancer, nasopharyngeal cancer, lung cancer, heart cancer, bone/cartilage cancer, breast cancer, other female genital organ cancer, cervical cancer, ovarian cancer, soft tissue neoplasm, skin cancer, testicular cancer, penile cancer, central nervous system cancer, endocrine cancer, lymphoma cancer, leukaemia cancer) were either self-reported or interviewed at the data collection phase, followed by harmonizing all of them according to the European coding system developed by European Union [28]. Bladder cancer cases were diagnosed and histologically confirmed throughe th study centres of the participanting individual studies, with International Classification of Diseases (ICD) 9 or 10. Through this, a pooled dataset with standard input was built up for further analysis. In addition to information on family history, the BLEND study includes data on: study characteristics (design, method of dietary assessment, recall time of dietary consumption and geographical region), participant demographics (age and sex), smoking status, passive smoking and smoking pack-years. Family history was evaluated using dichotomous variables (yes/no) distinguishing for bladder cancer or non-bladder cancer types among first- and second-degree relatives. Also, we considered the number of first- or second-degree relatives with total cancer types. The detailed information for inclusion criteria, study design, ascertainment of case and control, exposure assessment were performed in Supplementary Materials and Methods, Supplementary Table 1, and Supplementary Figure 1. Each participating study has been approved by the local ethic committee.

\section{Statistical analysis}

Descriptive statistics were utilized to determine frequencies, means, and standard deviations of all study variables, and the differences between cases and non-cases were assessed by Chi square test for categorical variables and $t$ test for continuous variables respectively. For categorical variables, i.e., ethnicity, missing data (9\%) was replaced by an indicator (using 0 as unknown); for continuous variables, i.e., smoking packyears, missing data (11\%) was replaced by the mean value of the smoking pack-years separated for sexes 
in each included individual study. No indicators were assigned for unknown information on family history in the present study.

To evaluate the associations between a positive family history of bladder cancer and non-bladder cancer types occurred in either first- or second-degree relatives and the risk of bladder cancer, multilevel logistic regression models were used to calculate odds ratios (ORs) and their associated 95\% confidence intervals (CI), which nested the individuals within study centres to adjust for cross-study heterogeneity. Models were adjusted: for 1) crude model without any adjustment; 2) age (years, continuous), sex (male or female) and ethnicity (Caucasian or non-Caucasian); 3) additionally adjusted for smoking status (never, current, or former smokers) and pack-years (cigarettes/day*years of smoking, continuous). To evaluate potential effect modification, the main interaction terms between family history (with or without any relative affected by cancer) and age, sex and smoking status were added to the model 3. Given the important role of age and smoking as bladder cancer determinants, we also performed stratified analyses upon the sex and smoking status though there was no or borderline interaction. P for trend test was conducted by assigning the groups of number of family history as a continuous variable in the models. The combined effect of smoking and a positive family history was also assessed. In addition, the impact of the number of positive family history relatives on bladder cancer risk was analysed, by comparing the family history of 1 and $>1$ affected relatives to non-family history.

Sensitivity analyses were performed by 1) additionally adjusting for passive smoking (unknown, nonpassive smoking and passive smoking); 2) removing the case-cohort study; and 3) conducting a metaanalysis by combining each individual study using a random-effect model. All analyses were conducted using STATA version 14 SE (Stata Corporation, Texas, USA). A significant two-tailed P value was set at 0.05 .

\section{Data Availability}

The data generated in this study are available upon request from the corresponding author. The data and code are not publicly available owing to their containing information that could compromise the privacy of research participants.

\section{Results}


The characteristics of the study participants are shown in Table 1. The mean age at recruitment among bladder cancer cases and non-cases were 60.49 and 61.41 years, respectively. Bladder cancer cases tended to be more frequently smokers $(81.58 \%)$ compared to non-cases $(62.92 \%)$, and to smoke more intensively with a longer duration (32.52 and 22.72 pack-years, respectively).

A positive family history of first-degree relatives was reported by $2.66 \%$ of all bladder cancer cases $(n=115)$ and $1.20 \%$ of all non-cases $(n=107)$. In addition, $2.60 \%$ of all bladder cancer cases reported a positive family history of second-degree relatives, while only $0.77 \%$ in non-cases. A similar significant pattern was observed for non-bladder cancer types (Table 1).

Based on the fully-adjustment model (model 3), individuals with a first-degree relative affected by bladder cancer showed an increased bladder cancer risk compared to individuals without any affected relative (OR 2.72, 95\%CI 1.55-4.77) (Table 2). Similarly, there was a positive association between having positive first-degree relatives affected by non-urologic cancer types and bladder cancer risk (OR 1.61, 95\%CI 1.192.18). A positive association of borderline statistical significance was observed for individuals with a firstdegree affected relative for other urological cancers. Family history in second-degree relatives only increased the bladder cancer risk when the second-degree relative was affected by bladder cancer (OR 1.71, 95\% CI 1.22-2.40), while non-bladder cancer types in second-degree relatives showed weak or no evidence of association with bladder cancer risk (Table 2).

The association of family history and bladder cancer risk seemed to increase with 1 and $>1$ first-degree relative affected by any cancer type (OR 1.42, 95\%CI 1.02-2.04; OR 2.67, 95\% CI 1.84-3.86, respectively; $\mathrm{P}$ for trend=0.032). In addition, we observed a positive association of family history and bladder cancer risk if $>1$ second-degree relative was affected by any cancers type, although the estimate was not greater than for just one affected relative (OR 1.88, 95\%CI 1.35-2.56) (Table 3).

The stratified analysis, shown in Table 4 that most of the results were consistent with results of the overall population, also showing that for both male and female the bladder cancer risk ( $\mathrm{P}$ for interaction $=0.321$ ) increases with having first-degree relatives affected by either bladder cancer (OR 2.16, 95\%CI 1.53-3.07; $2.11,95 \%$ CI $1.14-3.89$ ) or a non-bladder cancer type (OR 1.22, 95\%CI 1.06-1.41; $1.27,95 \%$ CI $1.08-1.80$ ) for males and females respectively, and having second-degree relatives affected by either bladder cancer (OR 2.82, 95\%CI 1.39-5.73; 2.12, 95\%CI 1.10-5.38) or a non-bladder cancer type (OR 1.74, 95\%CI $1.21-2.49 ; 2.0595 \%$ CI 1.10-3.84) for males and female respectively. 
Both current and former smokers were at an increased bladder cancer risk for individuals having a firstdegree relative affected by either bladder cancer (OR 1.77, 95\%CI 1.10-2.84; $1.83,95 \% \mathrm{CI} 1.14-2.94)$ or a non-bladder cancer type (OR 1.29, 95\%CI 1.05-1.57; 1.22, 95\%CI 1.01-1.50) for current and former smokers respectively, and having second-degree relatives affected by either bladder cancer (OR 3.06, 95\%CI $1.42-8.04 ; 3.92,95 \%$ CI 1.26-7.15) or a non-bladder cancer type OR 2.12, 95\%CI 1.22-3.69; 1.61 , 95\%CI 1.01-2.58) for current and former smokers respectively, while never-smokers only showed null associations. When considering the combined effect of a positive family history of bladder cancer and smoking, smokers without having a positive first-degree relative showed a positive association with bladder cancer risk compared to never-smokers without having a positive relative (OR 1.65, 95\%CI 1.451.87). This positive association doubled in magnitude for current and former smokers having a positive first-degree relative (OR 3.43, 95\%CI 2.39-4.91). Among never-smokers having a positive first-degree relative there was a non-statistically significant association with bladder cancer risk compared to neversmokers without having a positive relative (OR 1.67, 95\%CI 0.88-3.17). A similar pattern was shown for second-degree relatives (Supplementary Table 2).

Similar results under fully-adjustment model (model 3) were obtained after additionally adjusting for passive smoking (Supplementary Table 3), or removing the case-cohort study from the analysis (Supplementary Table 4 and 5). In addition, the meta-analysis approach also showed the consistent results: there was a significant increased bladder cancer risk for individuals having a first- or seconddegree bladder cancer affected relative (OR 1.68, 95\% CI 1.23-2.12; OR 1.47, 95\% CI 1.12-1.82, respectively); and current and former smokers with family history of all cancers showed a significantly increased risk of bladder cancer compared to never-smokers without a positive family history (OR 3.97, 95\%CI 2.82-5.12; 1.98, 95\% CI 1.45-2.52, respectively; Supplementary Figure 2).

\section{Discussion}

In this multicentric study we found that a first- and second-degree relative affected by bladder cancer increases the risk of bladder cancer. In addition, bladder cancer risk increased with an increment of relatives affected by any cancer type. Moreover, these findings were also found among never-smokers (although weaker), suggesting an independent effect of family history. 
Findings of the current paper are in line with most of the previously epidemiological studies on the effect of family history and bladder cancer risk, including a recent case-control study (Turati et al, 2017) [13], reporting a roughly two-fold bladder cancer risk for individuals having a bladder cancer affected relative. In addition, some earlier studies also demonstrated an elevated bladder cancer risks associated with an affected relative with bladder cancer, with estimates ranging from 1.20 to 4.0 [14, 16, 29-35]. However, all previous studies were only based on first-degree relatives, thereby, lacking evidence for the effect of having more distant affected relatives. To our knowledge, this is the first study showing an $70 \%$ increased bladder cancer risk for individuals having a second-degree affected relative, which strengths the evidence of inherited bladder cancer risk in more distant genetic relationships. If this finding is validated, family history among second-degree relatives could be considered when assessing an individual's bladder cancer risk. In addition, family history in second-degree relatives only increased the bladder cancer risk when the second-degree relative was affected by bladder cancer, this could be explained that patients with bladder cancer may remember bladder cancers among relatives better than other cancers.

A role for a familial component in bladder cancer development has also been suggested by other studies. Genome-wide association studies (GWASs) have identified many single nucleotide polymorphisms (SNPs) related to bladder cancer occurrence, including the identification of the NAT2-slow acetylator and GSMT1-null genotypes, which are highly associated with an increased bladder cancer risk [36-38]. In addition, it was reported that the overall proportion of variance corresponding to inherited factors for bladder cancer was $31 \%$ [39]. Recent data suggested that up to $13.4 \%$ of patients with bladder cancer have (likely) pathogenic mutations in previously identified cancer genes [40]. Moreover, a recent GWAS investigating the heritability and genetic correlation attributable to the additive effects of common SNPs found that the bladder cancer familial relative risk (FRR) was 1.37, defined as the increase in risk associated with the effects of GWAS identified SNPs [10].

In the present study, only weak association between bladder cancer and having a relative affected with urologic cancer types other than bladder cancer and non-urologic cancer types, suggesting that the influence of adjacent urinary tract or other sites on bladder cancer is limited. This is in line with a recent study which showed no association of bladder cancer risk and family history of non-bladder cancer sites [13]; however, the specific cancer type was unable to be examined due to the lack of sufficient data. 
Since smoking is the most important independent risk factor for bladder cancer risk and might interact with genetic defects for causing bladder cancer, this risk factor should be carefully considered when assessing the association between positive family history and bladder cancer. Smoking behaviour tends to cluster in families, thereby making it challenging to differentiate between smoking-related exposures, environmental exposures, and shared genes [41]. In the present study the combined effect of smoking and a positive bladder cancer family history yielded an almost 3.5-fold increased bladder cancer risk, while smoking and a positive family history alone yielded a roughly 1.5 -fold increased bladder cancer risk. Although the effect of a positive family history was not statistically significant among never smokers, this was likely due to the low statistical power. Nonetheless, the findings of present study suggest an independent effect of both factors on bladder cancer risk.

For the present study, data was pooled from 7 case-control and 1 case-cohort study, to obtain a sample size, large enough to permit detailed analyses with good precision. The study has some limitations; firstly, data on family history was self-reported, therefore, measurement error and misclassification due to recall bias are unavoidable, particularly for cancer types. It is suggested that individuals who suffer from a cancer tend to know other family members diagnosed with cancer, while those who are cancer free will be less informed on diagnosed family members, resulting in differential misclassification. However, it has been observed previously that the accuracy of reporting cancers in the first-degree relatives is generally high [34]. Unfortunately, this cannot be confirmed for second-degree relatives' data. Secondly, we did not have information about all other possible risk factors consistently across all studies included in these pooled analyses, other than age, sex, ethnicity, and smoking, such as body mass index (BMI), physical activity, socioeconomic status (SES), disinfection by-products, arsenic in the drinking water, and occupational exposures to potentially carcinogenic chemicals. Although, adjustments for these factors could have influenced the results, current literature shows that only a small proportion of bladder cancer cases can be attributed to these factors [42], and their correlation with family history is not well understood for all. Thirdly, the lack of information on either number of relatives or family size might introduce bias caused by different cancer occurrence rates among families. In addition, the lack of information on the age of siblings might influence the results, since the chance of having an affected sibling is greater among individuals with older siblings compared to individuals having younger siblings. Fourthly, for some bladder cancer subtypes, i.e., non-urothelial bladder cancer, it is known that they are mainly affected by infections (e.g., 
schistosomal and chronic cystitis) rather than genetic susceptibility, thereby possibly affecting our results. Unfortunately, due to lack of data on bladder cancer subtypes, we were unable to exclude non-urothelial cancer types. However, considering the proportion of non-urothelial bladder cancer is less than 3-5\% [43], the influence of this cancer type on our results are negligible. Lastly, although status as well as duration and intensity of smoking were considered, the adjustment for smoking might still be imperfect due to differences in smoking practices (e.g., depth of inhalation or amount of inhalation), or differences in types of smoke exposure [44]. Moreover, we lacked information on smoking history among relatives.

\section{Conclusion}

In summary, our results confirm previous epidemiological data reporting an increased bladder cancer risk with a positive bladder cancer family history in first- and second-degree relatives, and indicates a possible increased effect of a positive family history with an increment of numbers of affected relatives. Moreover, our findings suggest an added effect of smoking with family history on bladder cancer risk, and underline the importance of avoiding smoking, particularly in subjects with a family history of cancer.

\section{Role of Funder/Sponsor}

The funder had no role in the design and conduct of the study; collection, management, analysis, and interpretation of the data; preparation, review, or approval of the manuscript; and decision to submit the manuscript for publication.

\section{Acknowledgments}

We gratefully acknowledge all principal investigators for their willingness to participate in this jointed project. M.P. Zeegers was supported by the World Cancer Research Fund International (WCRF 2012/590), and European Commission (FP7-PEOPLE-618308). E.Y. Yu was supported by the Fundamental Research Funds for the Central Universities of China (4325002173)

\section{Author Contribution}

The authors' contributions were as follows; EYWY, MPZ and AW: conceived and designed the study; EYWY: conducted data analyses and interpretation and drafted the manuscript; MCS, XJ, LT, PvdB, CML, 
Author Manuscript Published OnlineFirst on January 13, 2022; DOI: 10.1158/1940-6207.CAPR-21-0490

Author manuscripts have been peer reviewed and accepted for publication but have not yet been edited.

MK, CLV, CB, JP, KG, ZZ, PV: provided the data; and all authors: read, revised, and approved the manuscript. 


\section{References}

1. Ferlay J, Soerjomataram I, Dikshit R, Eser S, Mathers C, Rebelo M, et al. Cancer incidence and mortality worldwide: sources, methods and major patterns in GLOBOCAN 2012. International journal of cancer. 2015;136(5):E359-86.

2. Siegel RL, Miller KD, Fuchs HE, Jemal A. Cancer Statistics, 2021. CA Cancer J Clin. 2021;71(1):7-33.

3. Antoni S, Ferlay J, Soerjomataram I, Znaor A, Jemal A, Bray F. Bladder Cancer Incidence and Mortality: A Global Overview and Recent Trends. Eur Urol. 2017;71(1):96-108.

4. Jemal A, Bray F, Center MM, Ferlay J, Ward E, Forman D. Global cancer statistics. CA: a cancer journal for clinicians. 2011;61(2):69-90.

5. Ploeg M, Aben KK, Kiemeney LA. The present and future burden of urinary bladder cancer in the world. World journal of urology. 2009;27(3):289-93.

6. Marugame T, Mizuno S. Comparison of prostate cancer mortality in five countries: France, Italy, Japan, UK and USA from the WHO mortality database (1960-2000). Jpn J Clin Oncol 2005;35(11):690-691.

7. Stewart B, Wild CP. World cancer report 2014. International Agency for Research on Cancer, World Health Organization: WHO Press, 2017.

8. Letašiová S, Medve'ová A, Šovčíková A, Dušinská M, Volkovová K, Mosoiu C, et al. Bladder cancer, a review of the environmental risk factors. Environmental health : a global access science source. 2012;11 Suppl 1(Suppl 1):S11.

9. Botteman MF, Pashos CL, Redaelli A, Laskin B, Hauser R. The health economics of bladder cancer: a comprehensive review of the published literature. Pharmacoeconomics. 2003;21(18):1315-30.

10. Sampson JN, Wheeler WA, Yeager M, Panagiotou O, Wang Z, Berndt SI, et al. Analysis of Heritability and Shared Heritability Based on Genome-Wide Association Studies for Thirteen Cancer Types. Journal of the National Cancer Institute. 2015;107(12):djv279.

11. Hemminki K, Bermejo JL, Ji J, Kumar R. Familial bladder cancer and the related genes. Current opinion in urology. 2011;21(5):386-92.

12. Mueller CM, Caporaso N, Greene MH. Familial and genetic risk of transitional cell carcinoma of the urinary tract. Urologic oncology. 2008;26(5):451-64.

13. Turati F, Bosetti C, Polesel J, Serraino D, Montella M, Libra M, et al. Family history of cancer and the risk of bladder cancer: A case-control study from Italy. Cancer Epidemiol. 2017;48:29-35. 
14. Aben KK, Witjes JA, Schoenberg MP, Hulsbergen-van de Kaa C, Verbeek AL, Kiemeney LA. Familial aggregation of urothelial cell carcinoma. International journal of cancer. 2002;98(2):274-8.

15. Goldgar DE, Easton DF, Cannon-Albright LA, Skolnick MH. Systematic population-based assessment of cancer risk in first-degree relatives of cancer probands. Journal of the National Cancer Institute. $1994 ; 86(21): 1600-8$.

16. Murta-Nascimento C, Silverman DT, Kogevinas M, García-Closas M, Rothman N, Tardón A, et al. Risk of bladder cancer associated with family history of cancer: do low-penetrance polymorphisms account for the increase in risk? Cancer epidemiology, biomarkers \& prevention : a publication of the American Association for Cancer Research, cosponsored by the American Society of Preventive Oncology. 2007;16(8):1595-600.

17. Mucci LA, Hjelmborg JB, Harris JR, Czene K, Havelick DJ, Scheike T, et al. Familial Risk and Heritability of Cancer Among Twins in Nordic Countries. Jama. 2016;315(1):68-76.

18. Goossens ME, Isa F, Brinkman $\mathrm{M}$ et al. International pooled study on diet and bladder cancer: the bladder cancer, epidemiology and nutritional determinants (BLEND) study: design and baseline characteristics. Archives of Public Health 2016;74(1):30-39.

19. Mettlin C, Graham S. Dietary risk factors in human bladder cancer. Am J Epidemiol. 1979;110(3):25563.

20. Cao W, Cai L, Rao JY, Pantuck A, Lu ML, Dalbagni G, et al. Tobacco smoking, GSTP1 polymorphism, and bladder carcinoma. Cancer. 2005;104(11):2400-8.

21. Jiang X, Castelao JE, Groshen S, Cortessis VK, Ross RK, Conti DV, et al. Alcohol consumption and risk of bladder cancer in Los Angeles County. International journal of cancer. 2007;121(4):839-45.

22. Wallace K, Kelsey KT, Schned A, Morris JS, Andrew AS, Karagas MR. Selenium and risk of bladder cancer: a population-based case-control study. Cancer Prev Res (Phila). 2009;2(1):70-3.

23. Shen M, Hung RJ, Brennan P, Malaveille C, Donato F, Placidi D, et al. Polymorphisms of the DNA repair genes XRCC1, XRCC3, XPD, interaction with environmental exposures, and bladder cancer risk in a case-control study in northern Italy. Cancer epidemiology, biomarkers \& prevention : a publication of the American Association for Cancer Research, cosponsored by the American Society of Preventive Oncology. 2003;12(11 Pt 1):1234-40.

24. Polesel J, Bosetti C, di Maso M, Montella M, Libra M, Garbeglio A, et al. Duration and intensity of tobacco smoking and the risk of papillary and non-papillary transitional cell carcinoma of the bladder. Cancer Causes Control. 2014;25(9):1151-8. 
25. Golka K, Heitmann P, Gieseler F, Hodzic J, Masche N, Bolt HM, et al. Elevated bladder cancer risk due to colorants--a statewide case-control study in North Rhine-Westphalia, Germany. J Toxicol Environ Health A. 2008;71(13-14):851-5.

26. van den Brandt PA, Goldbohm RA, van 't Veer P, Volovics A, Hermus RJ, Sturmans F. A large-scale prospective cohort study on diet and cancer in The Netherlands. Journal of clinical epidemiology. 1990;43(3):285-95.

27. Lu CM, Lan SJ, Lee YH, Huang JK, Huang CH, Hsieh CC. Tea consumption: fluid intake and bladder cancer risk in Southern Taiwan. Urology. 1999;54(5):823-8.

28. Poortvliet E, Klensin J, Kohlmeier L. Rationale document for the Eurocode 2 food coding system (version 91/2). Eur J Clin Nutr 1992;46(Suppl 5):S9-S24.

29. Kantor AF, Hartge P, Hoover RN, Fraumeni JF, Jr. Familial and environmental interactions in bladder cancer risk. International journal of cancer. 1985;35(6):703-6.

30. Cartwright RA. Genetic association with bladder cancer. Br Med J. 1979;2(6193):798.

31. Kunze E, Chang-Claude J, Frentzel-Beyme R. Life style and occupational risk factors for bladder cancer in Germany. A case-control study. Cancer. 1992;69(7):1776-90.

32. Piper JM, Matanoski GM, Tonascia J. Bladder cancer in young women. Am J Epidemiol. 1986;123(6):1033-42.

33. Kramer AA, Graham S, Burnett WS, Nasca P. Familial aggregation of bladder cancer stratified by smoking status. Epidemiology (Cambridge, Mass). 1991;2(2):145-8.

34. Lin J, Spitz MR, Dinney CP, Etzel CJ, Grossman HB, Wu X. Bladder cancer risk as modified by family history and smoking. Cancer. 2006;107(4):705-11.

35. Randi G, Pelucchi C, Negri E, Talamini R, Galeone C, Franceschi S, et al. Family history of urogenital cancers in patients with bladder, renal cell and prostate cancers. International journal of cancer. 2007; 121(12):2748-52.

36. Marcus PM, Vineis P, Rothman N. NAT2 slow acetylation and bladder cancer risk: a meta-analysis of 22 case-control studies conducted in the general population. Pharmacogenetics. 2000;10(2):115-22.

37. Engel LS, Taioli E, Pfeiffer R, Garcia-Closas M, Marcus PM, Lan Q, et al. Pooled analysis and metaanalysis of glutathione S-transferase M1 and bladder cancer: a HuGE review. Am J Epidemiol. 2002;156(2):95109. 
38. García-Closas M, Malats N, Silverman D, Dosemeci M, Kogevinas M, Hein DW, et al. NAT2 slow acetylation, GSTM1 null genotype, and risk of bladder cancer: results from the Spanish Bladder Cancer Study and meta-analyses. Lancet (London, England). 2005;366(9486):649-59.

39. Lichtenstein P, Holm NV, Verkasalo PK, Iliadou A, Kaprio J, Koskenvuo M, et al. Environmental and heritable factors in the causation of cancer--analyses of cohorts of twins from Sweden, Denmark, and Finland. The New England journal of medicine. 2000;343(2):78-85.

40. Carlo MI, Ravichandran V, Srinavasan P, Bandlamudi C, Kemel Y, Ceyhan-Birsoy O, et al. Cancer Susceptibility Mutations in Patients With Urothelial Malignancies. Journal of clinical oncology : official journal of the American Society of Clinical Oncology. 2020;38(5):406-14.

41. Martin C, Leiser CL, O'Neil B, Gupta S, Lowrance WT, Kohlmann W, et al. Familial Cancer Clustering in Urothelial Cancer: A Population-Based Case-Control Study. Journal of the National Cancer Institute. 2018;110(5):527-33.

42. Sugiyama K, Sugawara Y, Tomata Y, Nishino Y, Fukao A, Tsuji I. The association between coffee consumption and bladder cancer incidence in a pooled analysis of the Miyagi Cohort Study and Ohsaki Cohort Study. European journal of cancer prevention : the official journal of the European Cancer Prevention Organisation (ECP). 2017;26(2):125-30.

43. Dahm P, Gschwend JE. Malignant non-urothelial neoplasms of the urinary bladder: a review. Eur Urol. 2003;44(6):672-81.

44. Loftfield E, Freedman ND, Inoue-Choi M, Graubard BI, Sinha R. A Prospective Investigation of Coffee Drinking and Bladder Cancer Incidence in the United States. Epidemiology (Cambridge, Mass). 2017;28(5):685-93. 
Table 1 Characteristics of included participants and their family history by first- and second-degree relatives

\begin{tabular}{|c|c|c|c|c|c|c|}
\hline & \multicolumn{2}{|c|}{ Cases } & \multicolumn{2}{|c|}{ Non-cases } & \multirow{2}{*}{$\mathrm{P}$-value ${ }^{a}$} & \multirow{2}{*}{ P-interaction ${ }^{b}$} \\
\hline & No. & $\%$ & No. & $\%$ & & \\
\hline Sex & & & & & $<0.001$ & 0.321 \\
\hline Male & 3,506 & 81.03 & 5,494 & 61.40 & & \\
\hline Female & 821 & 18.97 & 3,454 & 38.60 & & \\
\hline $\operatorname{Age}(\operatorname{mean}(\mathrm{SD}))^{\mathrm{c}}$ & \multicolumn{2}{|c|}{$60.49(10.22)$} & \multicolumn{2}{|c|}{$61.41(8.29)$} & $<0.001$ & 0.437 \\
\hline$<55$ & 909 & 21.01 & 1,198 & 13.39 & $<0.001$ & \\
\hline $55-65$ & 1,925 & 44.49 & 4,784 & 53.46 & & \\
\hline$>65$ & 1,493 & 34.50 & 2,966 & 33.15 & & \\
\hline \multicolumn{7}{|l|}{ Smoking } \\
\hline Smoking status & & & & & & 0.048 \\
\hline Never & 797 & 18.42 & 3,318 & 37.08 & $<0.001$ & \\
\hline Current & 1,808 & 39.80 & 2,549 & 28.49 & & \\
\hline Former & 1,722 & 41.78 & 3,081 & 34.43 & & \\
\hline Smoking Pack-years (mean $(S D))^{d}$ & \multicolumn{2}{|c|}{$32.52(29.05)$} & \multicolumn{2}{|c|}{$22.72(24.83)$} & $<0.001$ & \\
\hline \multicolumn{7}{|l|}{ Ethinicity } \\
\hline Caucasian & 2,739 & 97.96 & 6,962 & 97.74 & $<0.001$ & \\
\hline Non-Caucasian & 57 & 2.04 & 161 & 2.26 & & \\
\hline \multicolumn{7}{|l|}{$\begin{array}{l}\text { Bladder cancer } \\
\text { (first-degree) }\end{array}$} \\
\hline Yes & 115 & 2.66 & 107 & 1.20 & $<0.001$ & \\
\hline No & 4,210 & 97.34 & 8,841 & 98.80 & & \\
\hline \multicolumn{7}{|l|}{$\begin{array}{l}\text { Bladder cancer } \\
\text { (second-degree) }\end{array}$} \\
\hline Yes & 39 & 2.60 & 16 & 0.77 & $<0.001$ & \\
\hline No & 1,461 & 97.40 & 2,070 & 99.23 & & \\
\hline \multicolumn{7}{|l|}{$\begin{array}{l}\text { Other urologic cancer } \\
\text { (first-degree) }\end{array}$} \\
\hline Yes & 55 & 2.16 & 126 & 1.84 & 0.015 & \\
\hline No & 2,489 & 97.84 & 6,717 & 98.16 & & \\
\hline
\end{tabular}




\begin{tabular}{|c|c|c|c|c|c|}
\hline Yes & 25 & 1.68 & 17 & 0.82 & 0.020 \\
\hline No & 1,467 & 98.32 & 2,054 & 99.18 & \\
\hline \multicolumn{6}{|l|}{$\begin{array}{l}\text { Non-urologic cancer } \\
\text { (first-degree) }\end{array}$} \\
\hline Yes & 535 & 12.36 & 1,575 & 17.60 & $<0.001$ \\
\hline No & 3,792 & 87.64 & 7,373 & 82.40 & \\
\hline $\begin{array}{l}\text { Non-urologic cancer } \\
\text { (second-degree) }\end{array}$ & & & & & $<0.001$ \\
\hline Yes & 117 & 7.78 & 95 & 4.54 & \\
\hline No & 1,387 & 92.22 & 1,997 & 95.46 & \\
\hline \multicolumn{6}{|l|}{$\begin{array}{l}\text { Number of family history } \\
\text { (first-degree) }\end{array}$} \\
\hline 0 & 793 & 61.62 & 3,503 & 68.58 & $<0.001$ \\
\hline 1 & 419 & 32.56 & 1,299 & 25.43 & \\
\hline$>1$ & 75 & 5.83 & 306 & 5.99 & \\
\hline \multicolumn{6}{|l|}{$\begin{array}{l}\text { Number of family history } \\
\text { (second-degree) }\end{array}$} \\
\hline 0 & 1,387 & 92.22 & 1,997 & 95.46 & $<0.001$ \\
\hline 1 & 102 & 6.78 & 81 & 3.87 & \\
\hline$>1$ & 15 & 1.00 & 14 & 0.67 & \\
\hline
\end{tabular}

${ }^{a}$ Calculated by Chi-square $\left(\chi^{2}\right)$ test for categorical variables and $t$-test for continuous variables between bladder cancer cases and non-cases.

${ }^{\mathrm{b}}$ To evaluate potential effect modification, P-interaction was calculated by adding the main interaction term between family history (with or without any relative affected by cancer) of cancer and age, sex, and smoking status to the age (continuous, years), sex (male or female), ethnicity (Caucasian or non-Caucasian), smoking status (never, current, or former) and smoking pack-years (continuous).

${ }^{\mathrm{c}}$ Age at the time of recruitment.

${ }^{\mathrm{d}}$ Pack-years was defined as the number of cigarettes smoked per day multiplying the years of smoking.

Abbreviation: SD, standard deviation.

P-value $<0.05$ was considered statistically significant.

P-interaction $<0.05$ was considered statistically significant.

Table 2 Bladder cancer risk for individuals with a positive family history of cancer in first- and second-degree relatives 


\begin{tabular}{|c|c|c|c|c|c|c|c|}
\hline \multirow{2}{*}{ Family History } & \multirow{2}{*}{ Case $(\mathbf{N})$} & \multicolumn{2}{|c|}{$\operatorname{Model~} 1^{\mathrm{e}}$} & \multicolumn{2}{|c|}{ Model $2^{f}$} & \multicolumn{2}{|c|}{ Model 3 ${ }^{\mathrm{f}, \mathrm{g}}$} \\
\hline & & OR & $95 \%$ & OR & $95 \%$ & OR & $95 \%$ \\
\hline \multicolumn{8}{|l|}{ First-degree } \\
\hline \multicolumn{8}{|l|}{ Bladder Cancer } \\
\hline No & 4,210 & 1.00 & & 1.00 & & 1.00 & \\
\hline Yes & 155 & 2.81 & $1.62-4.85$ & 2.66 & $1.52-4.63$ & 2.72 & $1.55-4.77$ \\
\hline \multicolumn{8}{|c|}{ Other Urologic Cancer } \\
\hline No & 2,489 & 1.00 & & 1.00 & & 1.00 & \\
\hline Yes & 55 & 1.99 & $1.06-3.75$ & 1.73 & $0.91-3.28$ & 1.83 & $0.96-3.50$ \\
\hline \multicolumn{8}{|c|}{ Non-urologic Cancer } \\
\hline No & 3,792 & 1.00 & & 1.00 & & 1.00 & \\
\hline Yes & 575 & 1.82 & $1.36-2.43$ & 1.58 & $1.17-2.13$ & 1.61 & $1.19-2.18$ \\
\hline \multicolumn{8}{|l|}{ Second-degree } \\
\hline \multicolumn{8}{|l|}{ Bladder Cancer } \\
\hline No & 1,461 & 1.00 & & 1.00 & & 1.00 & \\
\hline Yes & 46 & 1.91 & $1.44-2.52$ & 1.82 & $1.31-2.53$ & 1.71 & $1.22-2.40$ \\
\hline \multicolumn{8}{|c|}{ Other Urologic Cancer } \\
\hline No & 1,476 & 1.00 & & 1.00 & & 1.00 & \\
\hline Yes & 16 & 1.26 & $0.90-1.76$ & 1.25 & $0.89-1.76$ & 1.27 & $0.90-1.80$ \\
\hline \multicolumn{8}{|l|}{ Non-urologic Cancer } \\
\hline No & 1,387 & 1.00 & & 1.00 & & 1.00 & \\
\hline Yes & 124 & 1.20 & $1.06-1.35$ & 1.18 & $0.97-1.41$ & 1.06 & $0.76-1.42$ \\
\hline
\end{tabular}

${ }^{\mathrm{e}}$ Model 1: crude model without any adjustment.

${ }^{\mathrm{f}}$ Model 2: Adjusted for age (years, continuous), sex (male or female), ethnicity (Caucasian or non-Caucasian).

f, g Model 3: Additionally, smoking status (never, current, or former) and smoking pack-years (continuous).

Reference group was non-family history.

Table 3 Bladder cancer risk by the number of affected relatives 


\begin{tabular}{|c|c|c|c|c|c|c|c|c|}
\hline \multirow{2}{*}{ Family History } & \multirow{2}{*}{ Case $(\mathbf{N})$} & \multicolumn{2}{|c|}{ Model $1^{\mathrm{e}}$} & \multicolumn{2}{|c|}{$\operatorname{Model} 2^{f}$} & \multicolumn{2}{|c|}{ Model $3^{\mathrm{f}, \mathrm{g}}$} & \multirow[t]{2}{*}{ P-trend } \\
\hline & & OR & $95 \%$ & OR & $95 \%$ & OR & $95 \%$ & \\
\hline Number of First-degree & & & & & & & & 0.032 \\
\hline 0 & 1,387 & 1.00 & & 1.00 & & 1.00 & & \\
\hline 1 & 571 & 1.56 & $1.11-2.20$ & 1.51 & $1.07-2.14$ & 1.42 & $1.02-2.04$ & \\
\hline$>1$ & 129 & 2.62 & $1.87-3.66$ & 2.56 & $1.81-3.63$ & 2.67 & $1.84-3.86$ & \\
\hline Number of Second-degree & & & & & & & & 0.048 \\
\hline 0 & 1,005 & 1.00 & & 1.00 & & 1.00 & & \\
\hline 1 & 109 & 1.72 & $0.82-2.64$ & 1.73 & $0.82-2.65$ & 1.86 & $0.88-2.06$ & \\
\hline$>1$ & 15 & 1.81 & $1.32-2.48$ & 1.80 & $1.31-2.47$ & 1.88 & $1.35-2.56$ & \\
\hline
\end{tabular}

${ }^{\mathrm{e}}$ Model 1: crude model without any adjustment.

${ }^{\mathrm{f}}$ Model 2: Adjusted for age (years, continuous), sex (male or female), ethnicity (Caucasian or non-Caucasian).

${ }^{\mathrm{f}, \mathrm{g}}$ Model 3: Additionally, smoking status (never, current, or former) and smoking pack-years (continuous).

Reference group was non-family history.

P-trend $<0.05$ was considered statistically significant.

Table 4 Bladder cancer risk for having a positive family history stratified for sex and smoking status 


\begin{tabular}{|c|c|c|c|c|c|c|c|c|}
\hline \multirow{2}{*}{ Family History } & & \multirow{2}{*}{ Case $(\mathbf{N})$} & \multicolumn{2}{|c|}{ Model $1^{\mathrm{e}}$} & \multicolumn{2}{|c|}{$\operatorname{Model} 2^{\mathrm{f}}$} & \multicolumn{2}{|c|}{ 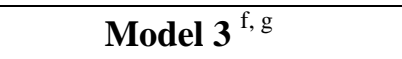 } \\
\hline & & & OR & $95 \%$ & OR & $95 \%$ & OR & $95 \%$ \\
\hline \multicolumn{9}{|l|}{ First-degree } \\
\hline \multicolumn{9}{|l|}{ Bladder Cancer } \\
\hline \multirow[t]{2}{*}{ Male } & No & 3,411 & 1.00 & & 1.00 & & 1.00 & \\
\hline & Yes & 93 & 2.24 & $1.59-3.17$ & 2.25 & $1.59-3.18$ & 2.16 & $1.53-3.07$ \\
\hline \multirow[t]{2}{*}{ Female } & No & 799 & 1.00 & & 1.00 & & 1.00 & \\
\hline & Yes & 22 & 2.11 & $1.15-3.90$ & 2.13 & $1.15-3.94$ & 2.11 & $1.14-3.89$ \\
\hline \multirow[t]{2}{*}{ Current Smoker } & No & 1,673 & 1.00 & & 1.00 & & 1.00 & \\
\hline & Yes & 49 & 1.69 & $1.06-2.70$ & 1.78 & $1.11-2.87$ & 1.77 & $1.10-2.84$ \\
\hline \multirow[t]{2}{*}{ Former Smoker } & No & 1,760 & 1.00 & & 1.00 & & 1.00 & \\
\hline & Yes & 47 & 1.84 & $1.15-2.95$ & 1.89 & $1.18-3.02$ & 1.83 & $1.14-2.94$ \\
\hline \multirow[t]{2}{*}{ Never Smoker } & No & 777 & 1.00 & & 1.00 & & 1.00 & \\
\hline & Yes & 19 & 1.44 & $0.81-2.58$ & 1.45 & $0.81-2.59$ & 1.38 & $0.77-2.47$ \\
\hline \multicolumn{9}{|c|}{ Non-Bladder Cancer } \\
\hline \multirow[t]{2}{*}{ Male } & No & 3,083 & 1.00 & & 1.00 & & 1.00 & \\
\hline & Yes & 423 & 1.25 & $1.08-1.44$ & 1.26 & $1.09-1.47$ & 1.22 & $1.06-1.41$ \\
\hline \multirow[t]{2}{*}{ Female } & No & 709 & 1.00 & & 1.00 & & 1.00 & \\
\hline & Yes & 112 & 1.26 & $1.03-1.76$ & 1.25 & $1.06-1.76$ & 1.27 & $1.08-1.80$ \\
\hline \multirow[t]{2}{*}{ Current Smoker } & No & 1,512 & 1.00 & & 1.00 & & 1.00 & \\
\hline & Yes & 210 & 1.25 & $1.02-1.53$ & 1.28 & $1.05-1.57$ & 1.29 & $1.05-1.57$ \\
\hline \multirow[t]{2}{*}{ Former Smoker } & No & 1,582 & 1.00 & & 1.00 & & 1.00 & \\
\hline & Yes & 226 & 1.24 & $1.02-1.51$ & 1.26 & $1.03-1.55$ & 1.22 & $1.01-1.50$ \\
\hline \multirow[t]{2}{*}{ Never Smoker } & No & 698 & 1.00 & & 1.00 & & 1.00 & \\
\hline & Yes & 99 & 1.13 & $0.87-1.48$ & 1.12 & $0.87-1.47$ & 1.12 & $0.86-1.46$ \\
\hline \multicolumn{9}{|l|}{ Second-degree } \\
\hline \multicolumn{9}{|l|}{ Bladder Cancer } \\
\hline \multirow[t]{2}{*}{ Male } & No & 1,127 & 1.00 & & 1.00 & & 1.00 & \\
\hline & Yes & 29 & 3.10 & $1.53-6.28$ & 2.75 & $1.35-5.58$ & 2.82 & $1.39-5.73$ \\
\hline
\end{tabular}




\begin{tabular}{|c|c|c|c|c|c|c|c|c|}
\hline \multirow[t]{2}{*}{ Female } & No & 334 & 1.00 & & 1.00 & & 1.00 & \\
\hline & Yes & 10 & 2.55 & $1.15-5.67$ & 2.21 & $1.13-6.63$ & 2.12 & $1.10-5.38$ \\
\hline \multirow[t]{2}{*}{ Current Smoker } & No & 474 & 1.00 & & 1.00 & & 1.00 & \\
\hline & Yes & 12 & 2.98 & $1.40-7.78$ & 3.01 & $1.46-8.97$ & 3.06 & $1.42-8.04$ \\
\hline \multirow[t]{2}{*}{ Former Smoker } & No & 634 & 1.00 & & 1.00 & & 1.00 & \\
\hline & Yes & 20 & 3.99 & $1.29-7.38$ & 3.55 & $1.14-7.08$ & 3.92 & $1.26-7.15$ \\
\hline \multirow[t]{2}{*}{ Never Smoker } & No & 353 & 1.00 & & 1.00 & & 1.00 & \\
\hline & Yes & 7 & 1.51 & $0.54-4.24$ & 1.14 & $0.39-3.32$ & 1.57 & $0.56-4.43$ \\
\hline \multicolumn{9}{|c|}{ Non-Bladder Cancer } \\
\hline \multirow[t]{2}{*}{ Male } & No & 3,429 & 1.00 & & 1.00 & & 1.00 & \\
\hline & Yes & 77 & 1.66 & $1.16-2.37$ & 1.67 & $1.17-2.38$ & 1.74 & $1.21-2.49$ \\
\hline \multirow[t]{2}{*}{ Female } & No & 781 & 1.00 & & 1.00 & & 1.00 & \\
\hline & Yes & 40 & 1.76 & $0.95-3.27$ & 2.20 & $1.17-4.14$ & 2.05 & $1.10-3.84$ \\
\hline \multirow[t]{2}{*}{ Current Smoker } & No & 1,696 & 1.00 & & 1.00 & & 1.00 & \\
\hline & Yes & 26 & 2.56 & $0.85-4.68$ & 2.07 & $1.20-3.57$ & 2.12 & $1.22-3.69$ \\
\hline \multirow[t]{2}{*}{ Former Smoker } & No & 1,760 & 1.00 & & 1.00 & & 1.00 & \\
\hline & Yes & 48 & 1.52 & $0.95-2.42$ & 1.66 & $1.03-2.68$ & 1.61 & $1.01-2.58$ \\
\hline \multirow[t]{2}{*}{ Never Smoker } & No & 754 & 1.00 & & 1.00 & & 1.00 & \\
\hline & Yes & 43 & 1.19 & $0.77-1.84$ & 1.39 & $0.92-2.10$ & 1.40 & $0.92-2.13$ \\
\hline
\end{tabular}

${ }^{\mathrm{e}}$ Model 1: crude model without any adjustment.

${ }^{\mathrm{f}}$ Model 2: Adjusted for age (years, continuous), sex (male or female), ethnicity (Caucasian or non-Caucasian).

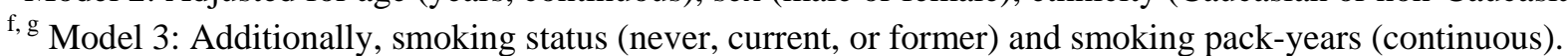

Reference group was non-family history. 


\section{Cancer Prevention Research}

\section{Family history and risk of bladder cancer: an analysis accounting for first- and second-degree relatives}

Evan Yi-Wen Yu, Mariana C Stern, Xuejuan Jiang, et al.

Cancer Prev Res Published OnlineFirst January 13, 2022.

\begin{tabular}{|rl} 
Updated version & $\begin{array}{l}\text { Access the most recent version of this article at: } \\
\text { doi:10.1158/1940-6207.CAPR-21-0490 }\end{array}$ \\
$\begin{aligned} \text { Supplementary } \\
\text { Material }\end{aligned}$ & $\begin{array}{l}\text { Access the most recent supplemental material at: } \\
\text { http://cancerpreventionresearch.aacrjournals.org/content/suppl/2022/01/11/1940-6207.CAPR-2 } \\
1-0490 . D C 1\end{array}$ \\
$\begin{array}{r}\text { Author } \\
\text { Manuscript }\end{array}$ & $\begin{array}{l}\text { Author manuscripts have been peer reviewed and accepted for publication but have not yet } \\
\text { been edited. }\end{array}$
\end{tabular}

E-mail alerts Sign up to receive free email-alerts related to this article or journal.

Reprints and

To order reprints of this article or to subscribe to the journal, contact the AACR Publications Subscriptions Department at pubs@aacr.org.

Permissions

To request permission to re-use all or part of this article, use this link http://cancerpreventionresearch.aacrjournals.org/content/early/2022/01/13/1940-6207.CAPR-21 -0490 .

Click on "Request Permissions" which will take you to the Copyright Clearance Center's (CCC) Rightslink site. 